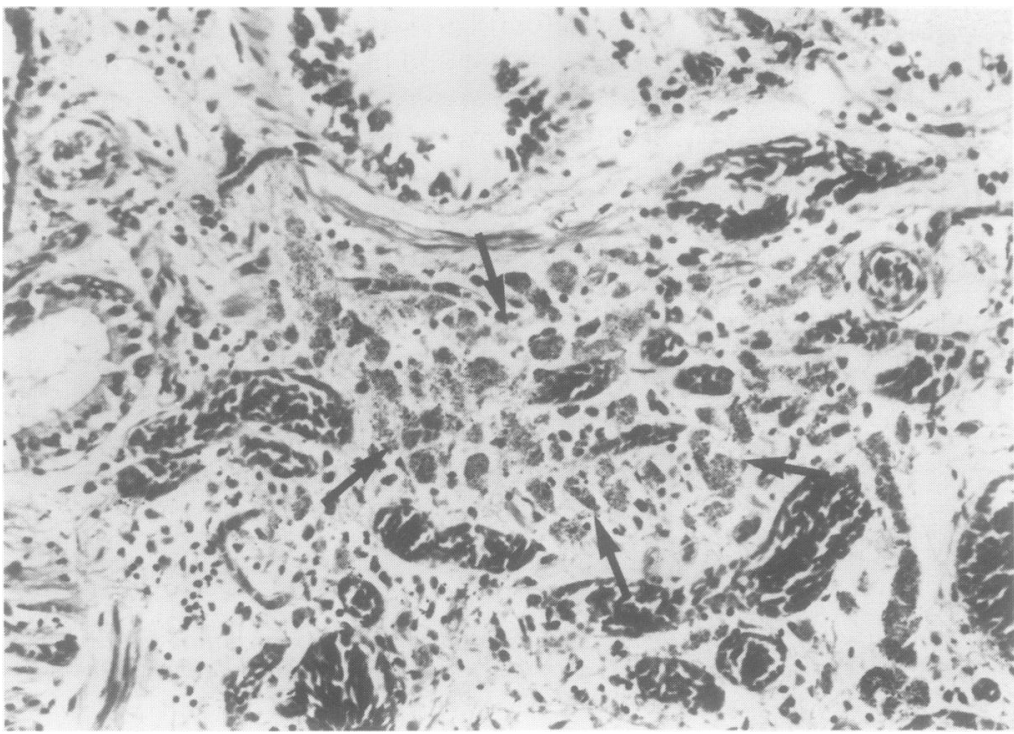

Figure 2 Photomicrograph of interstitium showing chronic inflammatory infiltrate with large numbers of pigment laden macrophages. Original magnification $\times 250$, reduced to $63 \%$ in origination.

cases with associated pulmonary fibrosis, ${ }^{12-10}$ only two of which underwent postmortem examinations. ${ }^{18}$ The pulmonary disease appears to be twice as common in women, ${ }^{10}$ occurring between the third and fourth decades. ${ }^{5}$ Onset of dyspnoea may range from weeks to years and there may be associated weight loss..$^{5}$ Progression to end stage fibrosis and death is recognised. ${ }^{10}$ Chest radiography reveals ill defined densities giving a ground glass appearance progressing to a diffuse reticulonodular pattern and honeycombing. ${ }^{2510}$ Pulmonary function is similar to that of other causes of parenchymal lung disorders.

The pathogenesis of the syndrome is un- clear. The hallmark of the syndrome is ceroid lipofuscin like inclusions throughout the entire reticuloendothelial system. Ceroid, a complex chromolipid, originates from oxidation of unsaturated fatty acids, accumulation resulting from possibly excessive phagocytosis of unsaturated lipids and/or congenital inadequacy to catabolise these lipids. ${ }^{5}$ Although pulmonary macrophages exhibit ceroid deposition, it is unclear whether ceroid is a passive byproduct or induces fibrosis. Alternatively, recurrent haemorrhage with resulting haemosiderosis has been suggested as a possible mechanism for pulmonary fibrosis. ${ }^{2}$

1 Hermansky F, Pudlak P. Albinism associated with haemorrhagic diathesis and unusual pigmented reticular cells in the bone marrow: report of two cases with histochemical studies. Blood 1959;14:162-9.

2 Davies BH, Tuddenham EGD. Familial pulmonary fibrosis associated with oculocutaneous albinism and platelet function defect. A new syndrome. $Q \mathcal{F} M$ ed 1976;178:21932 .

3 Bednar B, Hermansky F, Lojda Z. Vascular pseudohemophilia associated with ceroid pigmentoplagia in albinos. Am ₹ Pathol 1964;45:283-91.

4 Witkop Jr CJ, White JG, King RA. Oculocutaneous albinism. In: Nyham WL, ed. Heritable disorders of amino acid metabolism. New York: John Wiley, 1974:177

5 Garay SM, Gardella JE, Fazzini EP, Goldring RM. Hermansky Pudlak syndrome. Pulmonary manifestations of a ceroid storage disorder. Am $f$ Med 1979;66:737-47.

6 Hoste P, Williams J, Devriendt J, Lamont H, Van Der Straeten M. Familial diffuse interstitial pulmonary fibrosis associated with oculocutaneous albinism. Scand $f$ Respir Dis 1979;60:126-34

7 White DA, Walker Smith EJ, Cooper Jr JD, Glickstein M Rankin JA. Hermansky Pudlak syndrome and interstitia lung disease: report of a case with lavage findings. $A m R e v$ Respir Dis 1984;130:138-41.

8 Takahashi A, Yokoyama T. Hermansky Pudlak syndrome with special reference to lyosomal dysfunction. A case report and review of the literature. Virchows Arch A report and review of the literature. Virchor
Pathol Anat Histopathol 1984;402:247-58.

9 Schinella RA, Greco MA, Cobert BL, Denmark LW, Cox RP. Hermansky Pudlak syndrome with granulomatous colitis. Ann Intern Med 1980; 92: 20-3.

10 Depinho RA, Kaplan KL. The Hermansky Pudlak syndrome. Report of three cases and review of pathophysiology and management considerations. Medicine (Baltimore) 1985;64:192-202.

\section{Osteochondroma of the}

Royal Brompton

National Heart and Lung Hospital, London SW3 6HP

N K Harrison

J Wilkinson

D Hansell

M N Sheppard

P G Goldstraw

A J Newman Taylor

Southend Hospital, Westcliff-on-Sea,

Essex

J O'Donohue

A G Davison

Reprint requests to:

Dr N K Harrison.

Received 20 April 1993

Returned to authors

28 May 1993

Revised version received

5 August 1993

5 August 1993

17 August 1993

\section{rib: an unusual cause of haemothorax}

N K Harrison, J Wilkinson,

J O'Donohue, D Hansell,

M N Sheppard, P G Goldstraw,

A G Davison, A J Newman Taylor

\author{
Abstract \\ The case is described of a 36 year old \\ woman who presented with a large left \\ sided haemothorax. A thoracic computed \\ tomographic (CT) scan suggested there \\ was a bony outgrowth arising from the
}

fourth rib. This was resected surgically and found to be an osteochondroma which was surrounded by blood clot. No definite site of bleeding was identified, but it is thought that the tumour may have traumatised the lung, the pericardiacophrenic artery, or the superior pulmonary vein, resulting in life threatening haemorrhage.

(Thorax 1994;49:618-619)

Primary tumours of the thoracic cage are rare, accounting for only $7-8 \%$ of primary bone tumours. ${ }^{12}$ In a recent series of 90 primary bone tumours affecting the thorax four were osteochondromas, but only one of these occurred in a rib. ${ }^{3}$ We report an osteochondroma of the fourth rib which presented as a large haemothorax. 


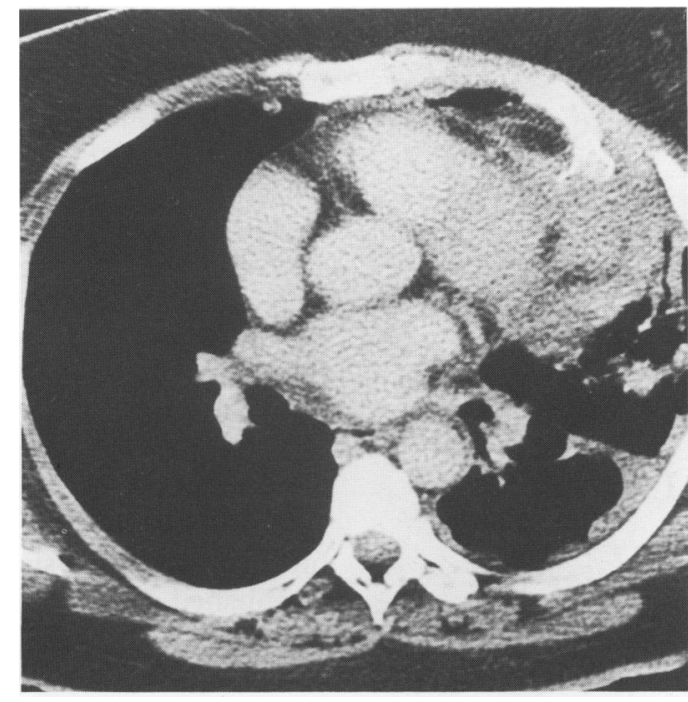

Figure 1 Computed tomographic scan with intravenous contrast showing a bony spur arising from the anterior end of the fourth rib projecting into a soft tissue mass. $A$ blood clot can be seen in the left pleural space.

\section{Case report}

A 36 year old woman presented with sudden onset of severe left sided pleuritic chest pain and breathlessness. On physical examination she had the signs of a left sided pleural effusion. There were no palpable abnormalities of the chest wall and she had no evidence of exostoses elsewhere. A chest radiograph confirmed a large left pleural effusion. A chest drain was inserted and 2.51 of blood was removed. Her haemoglobin concentration was $9 \cdot 1 \mathrm{~g} / \mathrm{dl}$, white blood count $16.3 \times 10^{9} / 1$, platelets $341 \times 10^{9} / 1$. A clotting screen was normal as were urea, electrolytes, and biochemical tests of liver function. A computed tomographic scan of the thorax showed a mass of soft tissue density, $5 \mathrm{~cm}$ in diameter, abutting the left lower anterior chest wall and mediastinum. Projecting into the centre of this mass was a calcified spur continuous with the cortex of the underlying fourth rib (fig 1). The anterior mediastinum was normal and there was no lymphadenopathy. She underwent an exploratory thoracotomy. At operation a bony exosto-

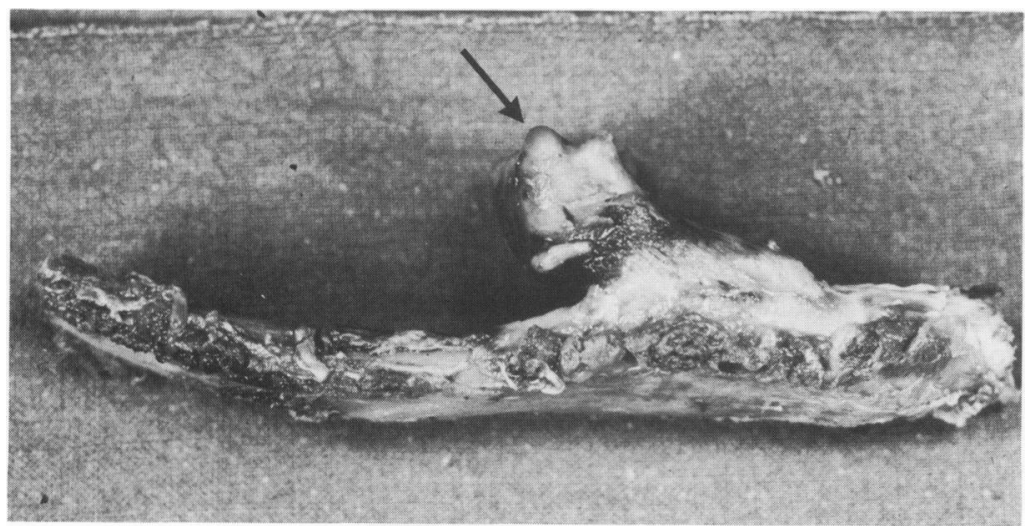

Figure 2 Rib showing a cartilage covered irregular mass (arrow) typical of an osteochondroma. sis was found arising from the posterior aspect of the anterior end of the fourth rib. There was clot lying between the medial aspect of the lingular segments and the pericardium and the bony spur extended into this clot. On one side lay the pericardiacophrenic artery and on the other the lingular tributary of the superior pulmonary vein. There was no active source of bleeding but the position of the tumour suggested that it may have traumatised either the lung or blood vessels in its proximity. The abnormal segment of rib was excised and the clot removed. Her postoperative recovery was uneventful and there has been no recurrence of haemorrhage on follow up.

Histopathological examination of the rib revealed a $3 \mathrm{~cm}$ mass of bone covered by a cap of cartilage protruding from its surface (fig 2). Microscopic examination revealed features in keeping with an osteochondroma and there was no evidence of malignancy.

\section{Discussion}

Osteochondromas of the ribs are exceedingly rare. They may present as a swelling in the chest wall or as an incidental finding on the chest radiograph. ${ }^{1}$ Most are symptomless but they can give rise to pain ${ }^{1}$ and there has been a report of one affecting the first rib which gave rise to thoracic outlet syndrome. ${ }^{4}$ They occur more commonly in patients with multiple exostoses, ${ }^{56}$ but when solitary they are rarely diagnosed preoperatively. ${ }^{1}$ Furthermore, they can undergo malignant change giving rise to chondrosarcomas. ${ }^{127}$ As far as we are aware this is the first report of an osteochondroma causing a haemothorax. Although the CT scan suggested that a partially calcified tumour was related to the fourth rib, surgery was necessary to evacuate the blood clot, to establish the diagnosis, and to prevent further problems in the future. The site of bleeding in this case remains in doubt as no active bleeding was observed during surgery, but the proximity of the tumour to the lung and related vessels suggests that one of these structures was traumatised.

1 Walker DA, Newman RJ. Primary tumours of the thoracic skeleton: an audit of the Leeds regional bone tumour registry. Thorax 1990;45:850-5.

2 Ala-Kulju K, Ketonen P, Jarvinen A, Salo J, Luosto R. Primary tumours of the ribs. Scand $\mathcal{f}$ Thorac Cardiovasc Primary tumours of the
Surg 1988;22:97-100.

3 Teitelbaum SL. Twenty years' experience with intrinsic tumours of the bony thorax at a large institution. $\mathcal{f}$ Thorac Cardiovasc Surg 1972;63:776-82.

4 Rosset P, Martinat H, Barsotti J, Gaisne E. Osteogenic exostosis of the first rib: a rare cause of thoracic outlet syndrome. Rev Chirurg Orthoped Reparatr Appareil Moteur 1990;76:62-5.

5 Logeais Y, Solovei G, Gosset X, Ramjee MP, Cadot M, Verger J. Osteochondroma of the rib in multiple exostoses. Report of one case. F Chirurg 1978;115:229-32.

6 Fabaron F, Vandermarcq P, Pascard JP, Defaux F, Azais O, Barret $\mathrm{D}$, et al. Intrathoracic chondrosarcoma arising at a rib in a patient with multiple exostoses. If Radiol abaracnam $S$,

7 Sabaratnam S, Salama FD, Morgan WE, Harvey JA. Primary chest wall tumours. Ann Thorac Surg 1985;39:4-15. 